\section{Help needed for Eastern Europe}

SIR - I am a Hungarian researcher visiting the National Cancer Institute in the United States. I am pleased to learn (Nature 360, 504; 1992) that the Howard Hughes Medical Institute "is weighing the idea of supporting researchers in the republics of the former Soviet Union and Eastern Europe". Researchers who receive such grants will truly benefit. But the contrast between the amount of individual grants in the States and those being considered for scientists in Eastern Europe and Russia is very disappointing.

We in Eastern Europe are really in desperate need of funds for research. However, my three-year research experience in Austrian, UK and US laboratories and my ten-year experience in Hungary in the field of environmental carcinogenesis make me say that the sums being considered for individual grants are so low that they will hardly provide any help to any scientist in the region. Laboratory instruments, chemicals and small equipment cost the same, usually even more for us than for institutes in the West, probably because the market is much smaller in Eastern Europe. The only components of research that are cheaper there, sadly enough, are manpower and expertise. No wonder the Howard Hughes Medical Institute is cautious when planning expansion in that part of the world, but in my view, instead of "supporting" many projects with irrationally low amounts of money, fewer but well-selected and well-funded grants would provide more benefit for the recipients and for the scientific progress of these countries.

\section{Bernadette Schoket}

Department of Biochemistry,

National Institute of Public Health,

Gyali ut 2-6,

Budapest, H-1097 Hungary

\section{More interferons}

SIR - While writing a review on animal interferons, I found that a computer search of the literature identified 16 papers that referred to interferon-tau. These papers described many interesting features of this molecule which appeared to be identical to interferon gamma and has been identified in humans, mice and swine. My initial assumption was that this was a new nomenclature reflecting the molecule's T-cell origin. But I was unable to find a citation referencing this nomenclature or any relevant statement from the International Interferon Nomenclature Committee.

Another reading of some of the pap- ers, however, pointed to an alternative explanation - a persistent typographical error. When working in some wordprocessing programs, one is obliged to use ASCII codes for Greek letters. Unfortunately, there is no ASCII code for gamma, a source of enormous frustration to immunologists. The letter tau $(\tau)$ however, bears some resemblance to gamma $(\gamma)$ and could be inadvertently substituted. Indeed, in the past I have used tau as a temporary substitute for gamma in a rough draft. A call to an author of one of the papers confirmed indeed that the use of tau was a typographical error. The substitution of tau for gamma clearly occurs with sufficient frequency that a respectable literature has built up on the subject of interferontau.

The failure of our educational system to provide a classical education and the uncritical use of the word processor thus appear to have contributed to one of the major problems in modern immunology, the explosive growth in the number of cytokines. It also raises the possibility that other cyotokines or peptide chains do not exist except as persistent typographical errors.

\section{lan Tizzard}

Department of Veterinary Pathobiology, Texas Veterinary Medical Center,

Texas A\&M University,

College Station, Texas 77843-4467, USA

\section{Diet and cancer}

SIR - In the leading article on diet and breast cancer (Nature 359, 760; 1992) the author's conclusion, based on a single cohort study, that the fat-breast cancer hypothesis should be consigned to oblivion, is premature, to say the least. The association between dietary fat and breast cancer was first demonstrated in animal models more than 50 years ago. Since then, numerous studies, using chemical, viral and X-ray-induced mammary tumour models, have shown that high fat intake promotes mammary cancer. In addition, cross-country comparisons and studies of migrants from low to high risk countries support the fat hypothesis. Data from case-control and cohort studies (such as the Harvard Nurses Study) have yielded much less consistent results. One possible reason is that the range of fat intake within the US population is too narrow to make any difference in cancer risk.

Evidence from China, Japan and animal models suggests that protection occurs if the diet contains 20 per cent fat calories or less. If this is the case, the results of the Harvard study could be interpreted to mean that even the lowest quintile of fat intake in the US female population ( 27 per cent) is above the hypothetical threshold where dietary fat ceases to exert tumour-enhancing effects. Several dietary intervention trials in women at high risk for breast cancer are under way in Canada, Sweden and the United States to test this hypothesis. Feasibility studies already completed have shown that the stated goal of these trials, that is, reduction of fat intake to 20 per cent of total calories, can be achieved and maintained over a two-year period. Against this background, one would be hard pressed to conclude that the fat hypothesis is "little more than wishful thinking", particularly on the basis of a single, albeit large, cohort study.

Leonard A. Cohen

Division of Nutrition and Endocrinology, American Health Foundation,

Dana Road,

Valhalla, New York 10595, USA

\section{Fraud inquiries}

SIR - As officers of the Association of Researchers in Medicine and Science, we read with interest the recommendation of the inquiry into scientific misconduct at Michigan State University $(\mathrm{Na}$ ture 361, 287; 1993) that the university "should develop policies for resolving conflicts ... for handling allegations of scientific misconduct".

When one of our members recently obtained evidence that a graduate student had been fraudulently altering data and the head of department sided with the student without considering the evidence, it became clear to us that there exists no accepted mechanism in UK universities through which a scientist can appeal for arbitration, or indeed for help or advice, in a dispute of this kind. It would clearly be slow, costly and unnecessarily cruel to follow the American pattern.

Our association, which is concerned about the quality of scientific research, proposes that British universities should set up an independent body of scientists to which involved scientists could appeal. A possible model would be the General Medical Council except that it would be concerned solely with complaints made by scientists themselves. Members of professional societies, the Royal Society and editors of scientific journals could provide names in each case of suitable people who are properly independent. It would seem wise for the body to sit in private, to protect the interests of both whistleblower and accused and to avoid the expense of lawyers.

\section{Peter N. Campbell}

Janice Taverne

University College London,

London WC1E 6BT, UK

NATURE • VOL 361 . 25 FEBRUARY 1993 